\title{
Perineal canal repair using modified Tsuchida's technique
}

\author{
S. Manjiri, Jeevak Shetty, S. K. Padmalatha, Kush Luthra and Neehar Patil
}

\begin{abstract}
Background: The perineal canal is a rare variety of anorectal malformations, identified by different nomenclatures like $\mathrm{H}$ fistula, double termination of the alimentary canal, and anovestibular fistula. Various approaches to repair this anomaly have been proposed.

The present study aimed to review the results of perineal canal repair with modified Tsuchida's technique, in seven girls treated in our unit between 2014 and 2019. These were classified as acquired and congenital type of perineal canal, depending upon their clinical presentations.

Results: Of the total seven cases, it was found that three of them had a perineal abscess and persistent anovestibular fistula formation, and they underwent definitive repair of the perineal canal after 12 weeks as they did not respond to the conservative management. Four girls had congenital anovestibular fistula without infection. All the patients underwent covering colostomy and definitive repair by modified Tsuchida's technique. One patient had a recurrence of the fistula, due to early closure of colostomy and underwent redo repair. One patient with known immune deficiency died before colostomy closure due to severe sepsis. During the last follow-up, all six girls were continent (Kelly's score 6/6), and the perineum had healed well.

Conclusion: The perineal canal can be acquired or congenital. Irrespective of its etiology, modified Tsuchida's technique has been found to be an easy and satisfactory method of its repair.

Keywords: Anorectal malformation, Perineal canal, Modified Tsuchida's technique, Perineal canal
\end{abstract}

\section{Background}

The perineal canal is a type of anorectal malformation in which a fistulous tract is noted between the anterior wall of normally formed anal canal and the perineum or vestibule in females and in males between perineum or urethra [1]. According to the latest Krickenbeck's classification [2], it has been classified as a rare variety of anorectal malformation with the incidence being as low as $3-4 \%$. Its frequency is relatively high in the Asian population [3]. Most of them have been published as case reports and a few case series.

The literature states that the perineal canal can be either acquired or congenital [4]. Due to the rarity of the anomaly, different methods of management and surgical repair have been tried worldwide. The spectrum of anorectal

* Correspondence: manjiris@yahoo.com

MS Ramaiah Medical College, MSR Nagar, Gokula post, Bengaluru 560054, India malformations including perineal canal and H-type rectovestibular fistula has been treated by surgical techniques such as vestibulorectal pull through [5], perineal repair, posterior sagittal anorectoplasty, and anterior anorectoplasty [6]. The common mode of management consisting of primary colostomy followed by "simple closure" of the fistula [7] has been found to be associated with a high failure rate.

This study presented about the experience in managing seven cases of the perineal canal with the anterior rectal wall pull-through technique, which was proposed by Tsuchida et al. in 1984. [1]. This technique involved sigmoid colostomy, anterior rectal wall pull through, and followed by colostomy closure, which required 7-10 days of hospitalization [1]. In the present study, the clinical manifestations and the applied surgical technique outcomes are highlighted in order to show the ease of this technique in perineal canal repair.
Springer Open

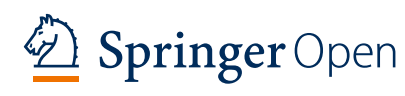

(c) The Author(s). 2020 Open Access This article is licensed under a Creative Commons Attribution 4.0 International License, which permits use, sharing, adaptation, distribution and reproduction in any medium or format, as long as you give appropriate credit to the original author(s) and the source, provide a link to the Creative Commons licence, and indicate if changes were made. The images or other third party material in this article are included in the article's Creative Commons licence, unless indicated otherwise in a credit line to the material. If material is not included in the article's Creative Commons licence and your intended use is not permitted by statutory regulation or exceeds the permitted use, you will need to obtain permission directly from the copyright holder. To view a copy of this licence, visit http://creativecommons.org/licenses/by/4.0/. 


\section{Methods}

The present retrospective review was conducted in the pediatric surgery unit of a tertiary care hospital. Patients' anonymity was maintained throughout the study. The study included seven female patients with anorectal malformation treated between 2014 and 2019. Of the total 70 cases of female anorectal malformations, seven girls aged between 2 months to 7 years had normally functioning anal canal with a perineal fistula (perineal canal) (Fig. 1).

They were reviewed with respect to clinical presentation, examination, and management. All patients were evaluated for associated anomalies. Patients who had perineal inflammation underwent diverting sigmoid colostomy at the first stage. They were treated with intravenous antibiotics and sitz bath and were reviewed after 12 weeks. A distal loopogram was done which revealed persistent fistula in the perineum. These patients were subjected to definitive repair once the perineal inflammation was controlled, and colostomy reversal was done at the third stage, after 12 weeks. Patients who presented with the perineal canal (without any inflammation) underwent a two-staged procedure which involved definitive repair with diverting sigmoid colostomy initially, followed by colostomy reversal after 12 weeks. All cases

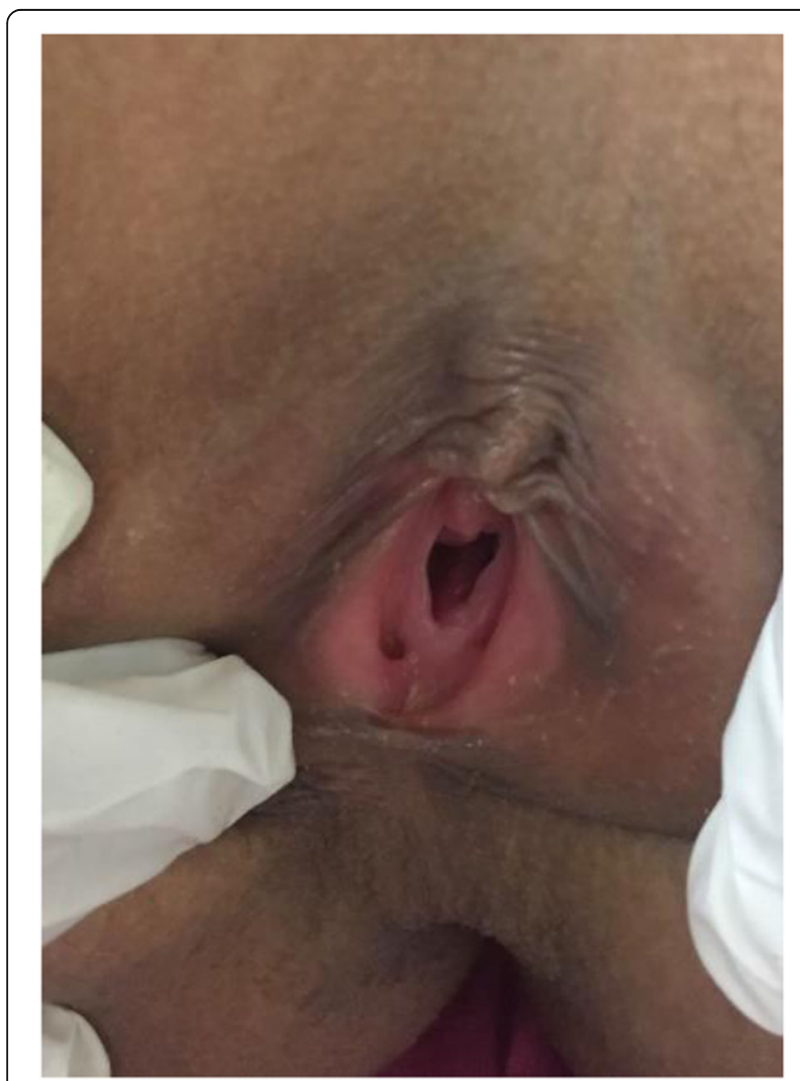

Fig. 1 Perineal canal: anolabial fistula without inflammation were given a thorough bowel preparation along with IV antibiotics prior to surgery.

\section{Operative technique}

The patient was placed in a lithotomy position. The fistulous tract was cannulated using a size 5 FG infant feeding tube (Fig. 2).

Stay sutures were taken at both ends of the fistulous opening, i.e., in the labial or vestibular site as well as the anal site. The anterior anal wall opening was within 1 $\mathrm{cm}$ of the anal verge in all cases. A semilunar incision was made over the anterior anal wall from 9 o'clock to 3 o'clock position. The fistulous tract was dissected from the perineal site, and the tract was traced till the anterior anal wall. The anterior anal wall was excised along with the fistula, through the perianal incision. The perineal body was reconstituted through the vestibular defect. The free intact proximal anterior wall of the rectum was directly sutured to the cutaneous tissue of the anus at its anterior circumference. The vestibular or labial site defect was closed using interrupted sutures. Vicryl no. 4-0 and 3-0 were used in all the cases.

Post-operatively, a per-urethral catheter was removed after 7 days. Antibiotics were given intravenously for 1 week. Analgesics in the form of iv paracetamol were given for 3 days only, and as and required then after. The child was discharged on the eighth postoperative day and was advised sitz bath twice daily at home. During follow-up, anal dilatation was advised after 2 weeks and continued for 3-4 months. All patients except one underwent closure of colostomy after 12 weeks of definitive repair. Due to personal reasons, early closure of stoma was done in a 7-year-old-female patient after clinically confirming that the perineum was healthy and healed, but recurrence of fistula due to an early closure of the stoma was seen.

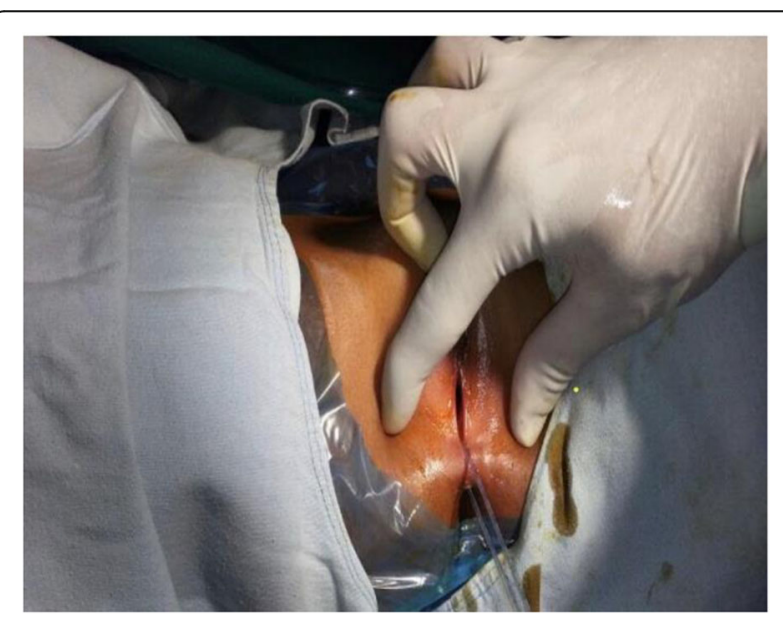

Fig. 2 Cannulation of the fistula from the anal canal to the vestibule (Tsuchida's procedure [1]) 


\section{Results}

In our series of the total 70 cases of female anorectal malformations, seven cases with perineal canal were noted (10\%). Out of seven girl subjects included in the study, three infants aged 20 days, 2 months, and 4 months, respectively, presented with a labial abscess which burst opened, resulting in anolabial fistula (Fig. 2). Four girls aged 2 months, 3 months, 7 years, and 8 years, respectively, presented with a passage of stools from a fistulous opening in the perineum, since birth, apart from having a normal anal canal since birth (Table 1), without any history of perineal abscess or inflammation.

On examination during initial admission, three infants had perineal inflammation, fever, and feculent discharge from the labial wound (Fig. 3).

The other four girls were clinically stable, afebrile, and had a well-formed fistulous tract in the perineum discharging stools without any inflammation. In all cases, there was a normal anal canal without any stenosis or malposition. Of the seven cases, five of them had a fistulous opening on the left labial region, one child had an opening in the vestibule in the midline, and another child had a fistulous opening over the right labial region. On the evaluation of associated anomalies, one infant was found to have associated cardiac anomaly atrial septal defect/ASD) and one infant had recurrent multiple infections and was diagnosed to have primary immunodeficiency syndrome (Table 2).

All the three infants, who underwent colostomy as the initial procedure for perineal inflammation following the rupture of a labial abscess, were reviewed after 12 weeks of conservative treatment. They had a persistent fistulous tract as confirmed with distal loopogram. They underwent anterior rectal wall pull through as second procedure and subsequently colostomy closure after 12 weeks of pull-through procedure. One child who underwent early closure of colostomy due to personal reasons had a recurrence of fistula. She underwent colostomy

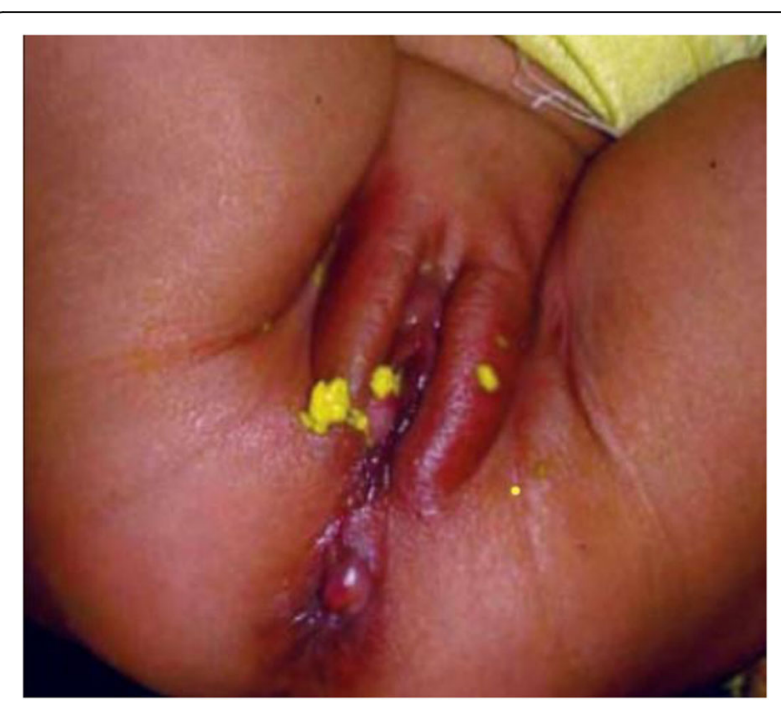

Fig. 3 Acquired fistula with perineal inflammation

again, and redo repair was done after 12 weeks, using the same method of repair. Colostomy was closed after 12 weeks, and the child was passing stools normally and only per rectally during subsequent follow-up visits. One baby with immunodeficiency syndrome died due to recurrent pneumonia. The other six patients were followed-up for 1-3 years and were continent, passing stools per rectally without any difficulty and with no recurrence of fistula. Functional evaluation was done using Kelly's scoring for continence, all patients had a score of $6 / 6$.

\section{Discussion}

The term perineal canal was described by Stephen and Smith for an anorectal malformation in which a fistulous tract is noted between the anterior wall of a normally formed anal canal and the perineum [8-14]. Various nomenclatures have been described for this anomaly, like double termination of the alimentary tract [1], anovestibular

Table 1 Reviewed cases of female anorectal malformations

\begin{tabular}{|c|c|c|c|c|}
\hline Case no. & Age & Presentation & Associated anomaly & Outcome \\
\hline 1. & 2 months & Labial abscess & None & Good \\
\hline 2. & 20 days & Labial abscess & None & Good \\
\hline 3. & 4 months & $\begin{array}{l}\text { Multiple subcutaneous } \\
\text { abscesses along with a } \\
\text { labial abscess }\end{array}$ & $\begin{array}{l}\text { Primary immunodeficiency } \\
\text { syndrome }\end{array}$ & $\begin{array}{l}\text { Expired due to severe } \\
\text { sepsis owing to } \\
\text { underlying } \\
\text { immunodeficiency }\end{array}$ \\
\hline 4. & 7 years & Ano vestibular fistula & None & Good \\
\hline 5. & 2 months & Anolabial fistula & ASD (right malrotated kidney) & Good \\
\hline 6. & 3 months & Anolabial fistula & None & Good \\
\hline 7. & 7 years & Anolabial fistula & None & $\begin{array}{l}\text { Recurrence of fistula- } \\
\text { colostomy, redo repair, } \\
\text { closure of colostomy }\end{array}$ \\
\hline
\end{tabular}


Table 2 Clinical features of reviewed cases of female anorectal malformations

\begin{tabular}{|c|c|c|c|c|c|c|}
\hline & \multirow{3}{*}{$\begin{array}{l}\text { Total } \\
\text { number } \\
\text { of } \\
\text { patients } \\
\text { reviewed }\end{array}$} & \multicolumn{5}{|c|}{ Clinical features } \\
\hline & & \multirow{2}{*}{$\begin{array}{l}\text { With } \\
\text { perineal } \\
\text { inflammation }\end{array}$} & \multirow{2}{*}{$\begin{array}{l}\text { Without } \\
\text { perineal } \\
\text { inflammation }\end{array}$} & \multirow{2}{*}{$\begin{array}{l}\text { Patients } \\
\text { with } \\
\text { associated } \\
\text { anomalies }\end{array}$} & \multicolumn{2}{|c|}{ Complications } \\
\hline & & & & & Death & Recurrence of fistula \\
\hline No. of patients & 7 & 3 & 4 & 2 & 1 & 1 \\
\hline
\end{tabular}

fistula [15], and $\mathrm{H}$ fistula $[5,6,16,17]$. It is a rare form of anorectal malformation according to Krikenbeck's classification [18]. It accounts for only $0.7 \%$ of the anorectal malformations [19]. However, the incidence is as high as $3.8-7 \%$ in Asian countries [20]. Two theories of etiology of this anomaly have been hypothesized, i.e., congenital and acquired type. In the congenital type, the parents observe passage of stools from an abnormal opening in the perineum, apart from the normal anal canal since birth [21]. Stephens proposed an impaired alignment of the two septa dividing internal cloaca as the etiology of H-type fistula (congenital) [22]. The acquired etiology has been suggested [11, 15] due to the associated perineal inflammation and vulvar abscess formation in some babies who did not have an additional opening at birth. Tsuchida et al., [1] during their study on 12 cases, observed that despite a normal anal canal, the failure of migration of uroanal and urorectal septum with an excessive posterior fusion of the genital folds might cause a partly patent or patent anovestibular fistula. They opined that the fistula occurred without inflammation in case of patent fistula and secondary to perineal inflammation in the case of partly patent fistula. The perineal opening site varies from the vestibule to the right or left labium in females and perineum or urethra in male children [1, 9, 15-17]. In our series, we found this anomaly in only female children, whereas three of them had perineal inflammation and abscess formation followed by fistula, while four girls presented with fistula, without any perineal inflammation. This is in accordance with other reports where the fistulous tract was reported to have a benign appearance without any inflammation $[8,23]$.

One child in the present study had fistulous opening along the midline in the vestibule, another had it in the right labium, and the rest of the five children had the opening in the left labium. Associated anal stenosis was found in a few previous cases in the literature and has been proposed as an important etiological factor $[1,16]$. However, none of our cases had anal stenosis. Chatterjee et al. [20] grouped their cases depending upon the location of the fistulous tract opening into the rectumabove the levator ani or below the levator ani, which could be diagnosed by radiological studies [1]. In our series, all the children had a fistulous connection in the anal canal, few millimeters from the anal verge, and distal loopogram was useful in locating the fistulous tract. Examination under anesthesia and endoscopy were other methods suggested [6] for localization of the fistulous opening in the anorectal canal.

The literature mentions that many of these cases were found to have associated anal stenosis or ectopic anus $[1,6,16,17]$. Cardiac and urological anomalies associated with perineal canal have also been reported $[1,6,9$, 16]. In our series, one case had malrotated right kidney and ASD (atrial septal defect) associated with perineal canal and one child had primary immunodeficiency syndrome causing recurrent episodes of infections.

Various techniques of managing perineal canal have been reported by different surgeons all around the world due to its unusual occurrence and etiological variations (acquired or congenital forms). Treatment in the form of antibiotics therapy and diversion colostomy is successful in a few cases of perineal inflammation causing fistula formation (acquired type) [9, 15], but recurrences have also been reported in these cases. However, in our series, conservative management did not help in any of the acquired fistula cases. In fact, some surgeons do not even recommend colostomy as a protective measure $[1,5,9]$. Colostomy alone does not cure the fistula [19]. Simple repair of the fistula is associated with a high recurrence rate $[1,9]$. Definitive repair in the form of vestibulorectal pull through [5, 24], perineal repair, posterior sagittal anorectoplasty, and anterior anorectoplasty [6] has been published at different centers with varying results.

Tsuchida et al. published their technique of perineal canal repair in 1984. In the case series of 12 females, they found 6 cases with perineal inflammation, 2 had associated stenosis of anal opening also, and 7 of their cases were repaired using this technique called pull through of anterior rectal wall. In this surgical technique, not only the fistulous tract but also the anterior half of the rectal wall below the fistula is totally excised through the perineal incision, and the normal proximal rectal wall is sutured to the anterior anal margin [1]. Of 7 cases, four cases had preceding colostomy (Table 3).

The modified Tsuchida's technique was popularized by Le Tan Son from Vietnam in 2011 shown in Table 3, showed incision into the anal wall margin, dissection of the anal wall in its anterior half beyond the fistulous opening, excision of the anal wall along with the fistula, and repair of the fistulous opening from the vestibular site, followed by approximation of the proximal free rectal wall to the anal margin [9]. 
Table 3 Tsuchida's technique/modified (anterior rectal wall pull through) technique of perineal canal repair

\begin{tabular}{llll}
\hline & $\begin{array}{l}\text { Our } \\
\text { series }\end{array}$ & $\begin{array}{c}\text { Tsuchida } \\
\text { et al. [1] }\end{array}$ & Le Tan Son [9] \\
\hline Total no. of female ARM & 70 & 86 & 210 \\
Perineal canal & 7 & 12 & 120 \\
With perineal inflammation & 3 & 6 & 86 \\
Without perineal inflammation & 4 & 6 & 34 \\
Associated anal stenosis & 0 & 2 & 0 \\
Anterior rectal wall pull & 7 & 7 & 118 \\
through repair & & & \\
colostomy & 7 & 4 & 28 \\
Recurrence of fistula & 1 & 0 & 4 \\
\hline
\end{tabular}

ARM Anorectal malformation

In our series, all our patients had covering colostomy and underwent modified Tsuchida's technique of pull through of anterior rectal wall, followed by the closure of colostomy after 12 weeks. We have found this technique very satisfactory in our hands. Initial management with antibiotics and diversion sigmoid colostomy was done in all the cases who had perineal inflammation, followed by elective repair using this technique. The major complications are fistula recurrence and wound dehiscence (25\%) [12]. In this study, there was one recurrence of fistula, and it was attributed to the early closure of colostomy after definitive perineal repair. The fecal continence represents the most important endpoint in patients with anorectal malformation; therefore, we have evaluated our patients by using Kelly scoring system (Table 4). A follow-up of 6 months to 3 years was done for the cases, and no complaints suggesting bowel dysfunction were found (Kelly's score 6/6).

The present study demonstrates the need to utilize all the possible resources for the restoration of severe anorectal malformations like the perineal canal. Our results gave good outcomes in terms of continence and anatomy.

Table 4 Kelly's scoring chart

\begin{tabular}{ll}
\hline Degree of fecal incontinence & Scoring \\
\hline Staining/smearing & None 2 \\
& Occasional 1 \\
Constant 0 \\
Accidental defecation/soiling & None 2 \\
& Occasional 1 \\
& Constant 0 \\
Strength of the perineal muscle & Strong 2 \\
& Weak 1 \\
& None 0 \\
\hline
\end{tabular}

\section{Conclusion}

The perineal canal is a rare form of anorectal malformation and can be diagnosed clinically without any elaborate investigations. Though the etiology may be congenital or acquired, surgical repair aimed at excision of the fistula is the definitive treatment for all these cases. Colostomy is advisable in both groups of patients for the healing of the perineal inflammation as well as for preventing the breakdown of perineal repair. Modified Tsuchida's technique $[1,9]$ of perineal repair has shown satisfactory results in this study. Apart from it being an easy procedure, the perineal body is kept intact, and extensive dissection is avoided. Adequate preparation and timing of operation are crucial factors for good results.

\section{Acknowledgements}

We acknowledge the cooperation of our patients and their parents/ guardians for giving us consent for this study.

\section{Authors' contributions}

The author MS has contributed by compiling the data and writing the manuscript. PK has contributed by collecting the clinical data. JS has contributed by providing clinical photographs. KL and NP have collected the references and literature review. All the authors have read and approved the revised manuscript for submission.

\section{Funding}

No funding source to declare.

\section{Availability of data and materials}

The data that support the findings of this study were collected from the hospital records and the availability of this data is restricted; however, it can be obtained on request from the hospital authorities.

\section{Ethics approval and consent to participate}

This study is approved by the Ethics Committee of Ramaiah Medical college, Bengaluru, India, Reg. No. ECR/215/Inst/KA/2013/RR-19. Informed verbal as well as written consent for publication of the data and photos has been obtained from the parents of the patients included in this study as per the institution's rule.

\section{Consent for publication}

Informed verbal as well as written consent for publication of the data and photos have been obtained from the parents of the patients included in this study as per the institution's rule.

\section{Competing interests}

The authors declare that they have no competing interests.

Received: 18 March 2020 Accepted: 8 April 2020

Published online: 13 May 2020

References

1. Tsuchida Y, Saito S, Honna T, Makino S, Kaneko M, et al. Double termination of the alimentary tract in females: a report of 12 cases and a literature review. J Pediatr Surg. 1984;19:292-6.

2. Gupta DK. Anorectal malformations - wingspread to Krickenbeck. J Indian Assoc Pediatr Surg. 2005;10(2).

3. Brem H, Guttman FM, Lagerg JM, Doody D. Congenital anal 4 with normal anus. J Pediatr Surg. 1989;24:183-5.

4. Rintala RJ, Mildh L, Lindahl H. H-type anorectal malformations: incidence and clinical characteristics. J Pediatr Surg. 1996;31:559-62.

5. Benno M. Ure, Risto J. Rintala, Alexander M. Holschneider. Scoring postoperative results. Anorectal malformations in children; A.M. Holschneider, J.M. Hustson, Page 351-59. 
6. Lawal TA, Chatoorgoon K, Bischoff A, Pena A, Levitt MA. Management of H-type rectovestibular and rectovaginal fistulas. J Pediatr Surg. 2011; 46:1226-30

7. Tsugawa C, Nishijima E, Muraji T, Satoh S, Kimura K. Surgical repair of rectovestibular fistula with normal anus. J Pediatr Surg. 1999;34(11):1703-5.

8. Wakhlu A, Pandey A, Prasad A, Kureel SN, Tandon RK, et al. Perineal canal. Pediatr Surg Int. 1997;12:283-5.

9. Son LT, Hung LT. Perineal canal: a special entity of anorectal malformations in Vietnam. Pediatr Surg Int. 2011;27:1105-7.

10. Rao KL, Choudhary SR, Samujh R, Narasimhan KL. Perineal canal repair by a new surgical technique. Peditr Surg Int. 1993;8:449-50.

11. Jiwane A, Kumar T, Kutumbale R, Bhusare D, Kothari P, Kulkarni B, et al. Perineal canal: an uncommon entity with good prognosis. J Indian Assoc Pediatr Surg. 2003;70(8):667-9.

12. Adel I. Perineal Canal: a simple method of repair. Pediatr Surg Int. 1994; 9:603-4.

13. Mirza I, Zia-ul-Miraj M. Management of perineal canal anomaly. Pediatr Surg Int. 1997;12(8):611-2

14. Stephens FD, Smith ED. Classification, identification and assessment of anorectal anomalies. Pediatr Surg Int. 1986;1:200-5.

15. Jain P, Mishra P, Shah H, Parelkar S, Borwankar SS. Anovestibular fistula with normal anal opening: is it always congenital? J Indian Assoc Pediatr Surg. 2008; $13: 137-9$

16. Tiwari C, Shah H, Bothra J, Kumbhar V. Anal stenosis with H-type rectourethral fistula in male. A rare anorectal malformation. Saudi Surg J. 2017;5:40-2.

17. Lawal TA, Eighemhenrio A, Kumolalo FO. Modified transanal repair of congenital H-type fistula. A technique to avoid recurrence. Afr J Paediatr Surg. 2013;10:38-40

18. Murphy F, Puri P, John M, Holschneider AM. Anorectal Malformations in children. Incidence and frequency of different types and classification of anorectal malformations. Germany: Springer-Verlag Berlin Heidelberg; 2006. p. 181

19. Rosen NG, Gibbs DL, Soffer SZ, Hong A, Sher M, Pepa A. The nonoperative management of fistula-in-ano. J Pediatr Surg. 2000;35:938-9.

20. Chaterjee SK. Double termination of the alimentary canal: a second look. J Pediatr Surg. 1980;15:623-7.

21. Yazlcl M, Etensel B, Gürsoy H, Özklsaclk S. Congenital H-type anovestibuler fistula. World J Gastroenterol. 2003;9(4):881-2.

22. Stephens FD, Smith ED. Anorectal malformations in children, vol. 51-96. Chicago: Yearbook Medical; 1971. p. 116-7.

23. Kulshrestha M, Prakash G, Gangopadhyay AN, Sarkar B. Management of congenital and acquired $\mathrm{H}$-type anorectal fistulae in girls by anterior sagittal anorectovaginoplasty. J Pediatr Surg. 1998;33:1224-8.

24. Bhaumik K, Das S, Chatterjee SK. Vestibulorectal pull through in $\mathrm{H}$ fistula in girls. J Indian Assoc Pediatr Surg. 2018;23:182-5.

\section{Publisher's Note}

Springer Nature remains neutral with regard to jurisdictional claims in published maps and institutional affiliations.

\section{Submit your manuscript to a SpringerOpen ${ }^{\circ}$ journal and benefit from:}

- Convenient online submission

- Rigorous peer review

- Open access: articles freely available online

- High visibility within the field

- Retaining the copyright to your article

Submit your next manuscript at $\boldsymbol{\nabla}$ springeropen.com 